\title{
Evaluation of Aerodynamic Forces over a Vertical Axis Wind Turbine Blade through CFD analysis
}

\author{
M. Saqib Hameed ${ }^{1 *}$ and Farzeen Shahid ${ }^{2}$ \\ ${ }^{1}$ COMSATS Institute of Information Technology, Sahiwal, Pakistan \\ ${ }^{2}$ HITEC University, Taxila Education City, Pakistan
}

\begin{abstract}
In the current age of global energy crisis, the production of energy through alternate energy resources has gained a significant attention. Wind as a source of energy is a very attractive due to the fact that fuel is free of cost in this case. This research is about the aerodynamic design of a VAWT blade using the analytical and CFD techniques for a small scale vertical axis wind turbine (VAWT), aiming $1 \mathrm{~kW}$ power output which may be use for domestic purposes to power a single room. The blade design parameters and dimensions are taken aiming the required power output and analytical models are developed to evaluate the aerodynamic forces like lift and drag over the surface of the blade. These forces which are very helpful for the evaluation of the structural integrity of the VAWT blade are then found to be in a close agreement with CFD results which are simulated using commercial software, ANSYS 13.0. The static CFD model is developed at a selected pitch angle during a complete $360^{\circ}$ where the aerodynamic forces evaluated are comparable with the analytical values at the similar location.
\end{abstract}

Keywords: SB-VAWT; Aerodynamic forces; Design parameters

\section{Introduction}

VAWTs has certain advantage over HAWTs which makes it favorable for installation in urban areas, like it gives a better response to turbulent wind flows when installed on buildings. Improving the wind turbine performance through wind tunnel testing and theoretical studies is expensive and consumes too much time. Aerodynamics blade analysis problems can be addressed by CFD simulations software which offers inexpensive solutions. Two dimensional airfoil models have been analyzed using ANSYS-FLUENT software and values of lift and drag coefficients obtained were compared with published calibrated values. The performance of small scale horizontal axis wind turbines have also been predicted using three dimensional models [1]. The inherent unsteady aerodynamic behavior of VAWTs is because of variation in angle of attack with pitch angle, viz. also the angle of rotation $(\theta)$ and apparent velocity. This complexity of unsteady aerodynamics makes VAWTs very attractive to be analyzed by CFD models [2]. The designed parameters including No. of blades, type of turbine, solidity and tip speed ratio have been evaluated for VAWTs using computational and experimental studies, in previous studies. K- $\varepsilon$ turbulence and multiple reference frame (MRF) models have been chosen to perform the transient simulations. CFD and experimental analyses may help to improve the performance of VAWTs [3], studied the performance of VAWTs by changing design parameters with fixed pitch angle using CFD simulations and wind tunnel experiments. Due to the three dimensional operation of VAWT, its aerodynamic performance is complex simulate. Different prediction tools for complex shaped VAWT performance evaluation were presented like integrating CAD and CFD existing software for solutions. Also, the mathematical models such as double multiple streamtube (DMS) models were discussed. All these VAWT solutions that already exist in market are lacking of technology innovation which may be due to the high complex aerodynamic prediction of VAWTs [4]. The dynamic stall for two dimensional flows around VAWT blades have also been investigated using CFD techniques and different turbulence models were compared with available data [5]. Attempts have also been made to study the flow physics of hybrid three bladed Darrieus-Savonius wind turbines using FLUENT [6]. SolidWorks and Star CCM+ have also been used for the development of geometry and carrying out the CFD analysis of wind turbines, respectively. The most effective airfoils were chosen on the basis of two dimensional and three dimensional analyses at different angles of attack and speeds in order to determine when flow separation takes place [7]. VAWT's performance and aerodynamic efficiency was confirmed using CFD analysis by designing a high efficiency $500 \mathrm{~W}$ composite VAWT blade, applicable in low speed regions of Korea [8].

This research is about the development of solid and CFD models of blade for small scale VAWT using Pro Engineer and ANSYS 13.0 CFX, respectively.

The technique is used to evaluate the aerodynamic forces like lift and drag using CFD analysis. These values are compared with the analytical values calculated in earlier research on the same VAWT blade.

The only $2 \mathrm{D}$ analysis of this blade would not produce the same values as calculated using analytical modeling because during the calculation of total forces along and normal to the chord length, the value of span length plays an important role. Increasing the span length increases the total force along each direction. Therefore, a complete 3D model is required to be analyzed in order to verify the results obtained in analytical modeling.

\section{Design constraints}

The value of wind speed is taken as $8 \mathrm{~m} / \mathrm{s}$ for the purpose of analysis, which is an average value at the areas where this wind turbine will be installed. The values of design parameters and blade dimensions are summarized in the table 1 .

${ }^{*}$ Corresponding author: M. Saqib Hameed, COMSATS Institute of Information Technology, Sahiwal, Pakistan, E-mail: saqibhameed@ciitsahiwal.edu.pk

Received November 22, 2012; Accepted December 30, 2012; Published January 03, 2013

Citation: Hameed MS, Shahid F (2012) Evaluation of Aerodynamic Forces over a Vertical Axis Wind Turbine Blade through CFD analysis. J Appl Mech Eng 1:116 doi:10.4172/2168-9873.1000116

Copyright: (c) 2012 Hameed MS, et al. This is an open-access article distributed under the terms of the Creative Commons Attribution License, which permits unrestricted use, distribution, and reproduction in any medium, provided the original author and source are credited. 
Citation: Hameed MS, Shahid F (2012) Evaluation of Aerodynamic Forces over a Vertical Axis Wind Turbine Blade through CFD analysis. J Appl Mech Eng 1:116 doi:10.4172/2168-9873.1000116

Page 2 of 6

\begin{tabular}{|c|c|c|c|}
\hline $\begin{array}{c}\text { Design Parameter } \\
\text { Total Number of Blades } \\
\text { (n) }\end{array}$ & $\begin{array}{c}\text { Relationships } \\
\text { used for } \\
\text { Calculations }\end{array}$ & $\begin{array}{c}\text { Given/Recommended } \\
\text { Range for VAWT }\end{array}$ & $\begin{array}{c}\text { Selected/ } \\
\text { Calculated } \\
\text { Value }\end{array}$ \\
\hline $\begin{array}{c}\text { Tip Speed Ratio (TSR) } \\
\text { Solidity }\end{array}$ & $\begin{array}{c}\lambda_{\text {max }}={ }^{4 \pi} / \mathrm{n}=\mathrm{R}_{\mathrm{w}} \mathrm{N} \\
\text { Solidity= } \frac{\mathrm{nc}}{\mathrm{D}}\end{array}$ & $0.1-0.25$ & 3 \\
\hline Power Coefficient (Cp) & $\begin{array}{c}\text { Solidity and TSR } \\
\text { Curve }\end{array}$ & 0.45 Max. & 0.24 \\
\hline $\begin{array}{c}\text { Swept Area (s) } \\
\mathrm{P}=0.5 \mathrm{C}_{\mathrm{p}} \rho \mathrm{sv}^{3}\end{array}$ & - & 0.43 \\
\hline $\begin{array}{c}\text { Diameter of the } \\
\text { Turbine (D)=Span } \\
\text { Length (b) }\end{array}$ & $\begin{array}{c}\text { Considering the } \\
\text { Square Box }\end{array}$ & & $6.76 \mathrm{~m}^{2}$ \\
\hline Aspect Ratio (AR) & - & - & $2.58 \mathrm{~m}$ \\
\hline Chord Length (c) & $\mathrm{AR}=\mathrm{b} / \mathrm{c}$ & - & 12.5 \\
\hline
\end{tabular}

Table 1: Selection of Blade Design Parameters.

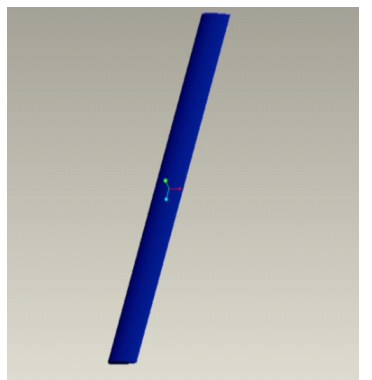

Figure 1: Solid Model of VAWT Blade.

\section{Airfoil for the VAWT blade}

Considering the importance of thickness of airfoil for a high value aspect ratio blade and the aerodynamic characteristics like life and drag coefficients, NACA 0015 was selected as the more suitable airfoil among the recommended family of airfoils, NACA 00XX.

\section{Evaluation of aerodynamic forces through CFD analysis}

The results obtained from the analytical analysis of the aerodynamic forces [9], are verified in this section using computation fluid dynamic (CFD) analysis.

\section{Construction of blade geometry}

A commercial software (Pro Engineer) is used for the construction of solid model of designed blade using the dimensions calculated in table 1 . The key points as input are entered to generate cross section (NACA0015 airfoil) of the blade. These key points are joined through spline curve it will form the shape of perfect symmetric blade with well defines leading and trailing edge, the cross section is then extruded to the designed value of blade span length. The blade and other components of turbine including disc, strips, bolts and shaft are model and assembled. A view of this design blade and a complete solid model of the 3 straight bladed VAWT are shown in figure 1 and figure 2 .

\section{Generation of mesh}

The blade solid model is imported to ICEM (ANSYS 13.0) in .iges format, (Figure 3). The transformation of geometry is done by offsetting the points from blade geometry to develop the far field. These offset points are joined by lines and then surfaces are created between those lines (Figure 4). These surfaces are then extruded in up and down direction which completely enclosed the blade (Figure 5). The geometry is divided into parts i.e. inlet, outlet, blade left, blade right so it get easy to mesh the whole geometry properly and later to study each part result separately.

\section{Blocking}

The geometry is joined to a series of blocks which make the actual volume so that the calculation will take place on those volumes or parts. Whole mesh geometry is selected for blocking (Figure 6).

The blocking allows turning off the certain surfaces which are not required in order to reduce the complexity of the mesh. The block is also spitted and associated with the blade surface in order to attach the mesh with the blade surface and reshape the mesh according to the contours of the blade.

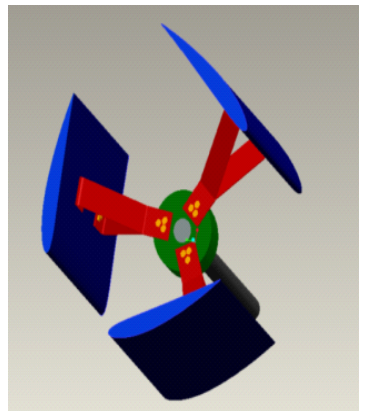

Figure 2: Solid Model of the Designed VAWT.

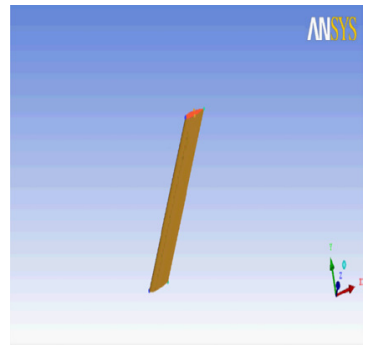

Figure 3: Blade model in ANSYS imported from Pro-E.

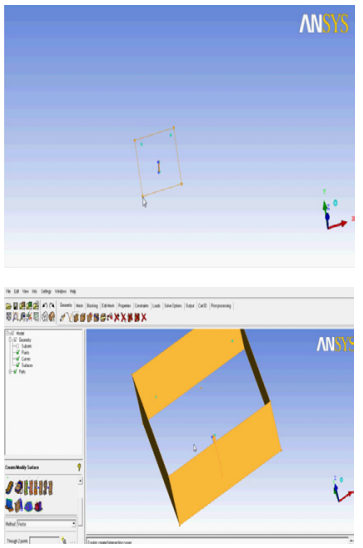

Figure 4: Creation of far field around blade for CFD analysis. 
Citation: Hameed MS, Shahid F (2012) Evaluation of Aerodynamic Forces over a Vertical Axis Wind Turbine Blade through CFD analysis. J Appl Mech Eng 1:116 doi:10.4172/2168-9873.1000116

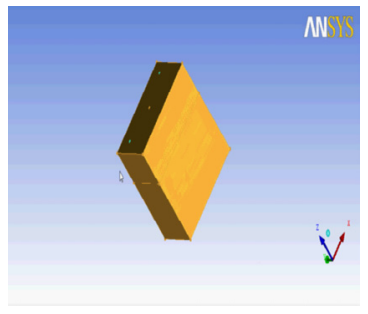

Figure 5: Complete far field.

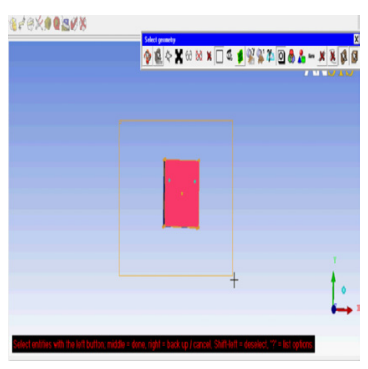

Figure 6: Blocking of blade

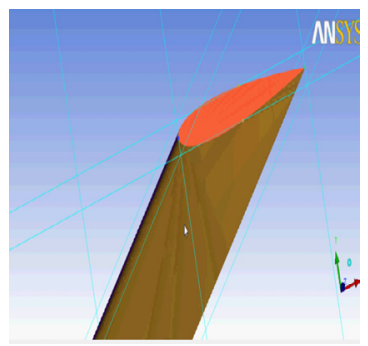

Figure 7: Wireframe model of mesh around blade surfaces.

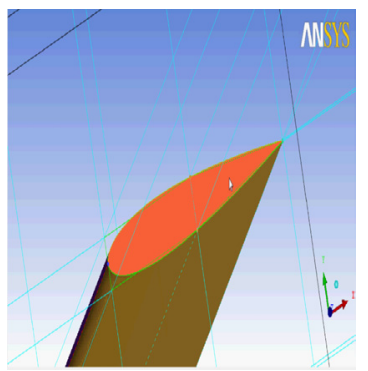

Figure 8: Blade Upper Surface Associated.

\section{Association}

The rectangular box in the wireframe model of mesh in enclosing the blade cross section (airfoil) in figure 7, The association is done in order to associate the straight line of block to the edges of blade so that the block take the shape of blade in figure 8 . The pre-mesh parameters are define, in which the number of nodes are entered. As the number of nodes increases the mesh will get more refined. Now, the mesh geometry is in accordance with the blade geometry and all the boundary layer properties after the analysis can be captured. When the blocking and association of mesh is done, the mesh over the blade has been modified and improved, (Figure 9).

\section{Clustering}

The clustering is performed to further refine the mesh close to the blade surfaces in order to achieve the improved results near the blade boundary/surface (Figure 10). This fine mesh is achieved by increasing the number of nodes (or distance between them).

\section{Grid resolution}

The grid quality is important and helpful for the reduction of computational errors. Bigeometric mesh law is considered to generate this grid. The size control for this grid shows that every line in the far field is divided into 25 parts and lines along blade cross section and span are divided in 20 parts. The total number of cells the complete grid are 863404 .

\section{Writing mesh for CFX PRE}

After clustering, the unstructured mesh is saved as blocking. The mesh is reloaded from blocking and regenerated then it is written to an input file for CFX PRE. This CFX file is made readable in ICEM mesh. Now, this file is reloaded in CFX PRE and primitive regions are inserted defining inlet, outlet and blade regions for CFX PRE.

Numerical simulation and turbulence model: The simulations are performed in ANSYS CFX 13.0 using Shear Stress Transport (SST) $\mathrm{k}-\omega$ turbulence model incorporating the Computational Finite Volume method for solution. Heat transfer by total energy is considered to make it a compressible fluid model in CFX-Pre.

\section{Setting up the domain}

In the airfoil domain basic settings, the material is set as Air Ideal Gas and reference pressure as $56.867 \mathrm{kPa}$. For compressible analysis, the heat transfer option is set to total energy. Viscous turbulence effects are also including by including the viscous work term in the domain.

\section{Boundary conditions}

The outlet relative pressure of $0 \mathrm{~Pa}$ is applied relative to the operating pressure of $56.867 \mathrm{kPa}$, as

\section{Absolute Pressure $=$ Reference Pressure + Relative Pressure}

The flow regime is subsonic and free stream velocity is taken as $8 \mathrm{~m} / \mathrm{s}$

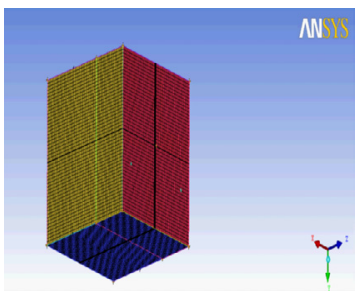

Figure 9: Complete mesh for CFD analysis.

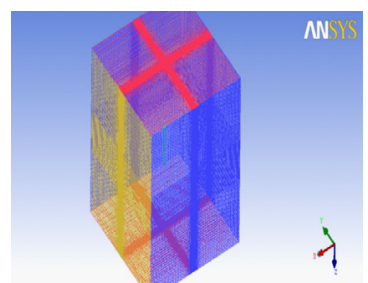

Figure 10: Clustering for improved results over the mesh. 
Citation: Hameed MS, Shahid F (2012) Evaluation of Aerodynamic Forces over a Vertical Axis Wind Turbine Blade through CFD analysis. J Appl Mech Eng 1:116 doi:10.4172/2168-9873.1000116

expressed as $\mathrm{U}_{\mathrm{inf}}$ in software expressions. This free stream velocity is divided into rectangular components along $\mathrm{x}$ and $\mathrm{y}$ directions whereas, component of velocity along $\mathrm{z}$ axis is taken as zero. Static temperature is chosen as $298 \mathrm{~K}$. The boundary conditions are inserted as blade and boundary type is set as wall and following expressions are used. The analysis is carried out at a single value of angle of attack, i.e. 8.36 degree.

In the convergence criteria the residual type is selected as root mean square (RMS) and the residual target is set as $10-6$

$$
\begin{aligned}
& \mathrm{AOA}=8.36[\mathrm{deg}]=\text { Angle of attack } \\
& \mathrm{Ux}=\mathrm{Uinf}^{*} \cos (\mathrm{AOA})=\text { Flow velocity along } \mathrm{x} \text { axis } \\
& \mathrm{Uy}=\mathrm{Uinf}^{\star} \sin (\mathrm{AOA})=\text { Flow velocity along } \mathrm{y} \text { axis } \\
& \mathrm{Fy}=\text { force_y }() @ \text { Blade=Normal force on blade } \\
& \mathrm{Fx}=\text { force_ } \mathrm{x}() @ \text { Blade=Axial force on blade } \\
& \mathrm{Lift}=\cos (\mathrm{AOA})^{\star} \mathrm{Fy}-\sin (\mathrm{AOA})^{\star} \mathrm{Fx}=\mathrm{Lift} \text { force } \\
& \text { Drag }=\cos (\mathrm{AOA})^{\star} \mathrm{Fx}+\sin (\mathrm{AOA})^{\star} \mathrm{Fy}=\text { Drag force }
\end{aligned}
$$

Denom $=0.5^{\star}$ massFlowAve(Density)@Inlet ${ }^{\star} \operatorname{Uinf}^{\wedge} 2^{\star} 0.206[\mathrm{~m}]^{\star} 2.58[\mathrm{~m}]$

\section{$\mathrm{CL}=\mathrm{Lift} /$ Denom $=$ Coefficient of Lift}

$\mathrm{CD}=$ Drag/Denom=Coefficient of Drag

\section{Solver control}

In the solver control tree, the maximum iterations are set to 2000 and timescale factor is 1 to 10 as, a large scale factor can accelerate the convergence but too large timescale may cause the solver to fail. The residual target is set to 1-6. The case is now ready to run for solution.

\section{Findings of research}

After, all the boundary conditions are applied and solution is completely, a result file is formed which can be open in post CFX for the evaluation of results.

1) Results obtained from CFD analysis are compared with the analytical solution of the same problem, which was done in the earlier research [9], the comparison of results is summarized in table 2.

2) The figure 11 shows higher values of velocity on the upper region of the blade, as the blade shown here is upside down (showing y axis downwards).

3) The higher values of velocity on upper regions make reduction in pressure in the same regions, which can be seen in figure 12. The higher pressure in lower region and lower pressure on upper region; the difference between both creates the lift force in the blade, which drives the turbine.

\begin{tabular}{|c|c|c|c|c|}
\hline \multicolumn{5}{|c|}{ NUMERICAL RESULTS (Obtained from CFX) } \\
\hline AOA (deg) & LIFT & DRAG & TANGENTIAL & NORMAL \\
\hline 8.36 & 546.15 & 12.69 & 72.00 & 543.79 \\
\hline \multicolumn{5}{|c|}{ ANALYTICAL RESULTS [9] } \\
\hline AOA (deg) & LIFT & DRAG & TANGENTIAL & NORMAL \\
\hline 5.74 & 371.6 & 9.27 & 28.00 & 370.72 \\
\hline $\mathbf{8 . 3 6}$ & $\mathbf{5 5 2 . 0 9}$ & $\mathbf{1 1 . 4 9}$ & $\mathbf{6 8 . 9 7}$ & $\mathbf{5 4 7 . 8 9}$ \\
\hline 10.66 & 659.63 & 13.62 & 108.65 & 650.77 \\
\hline \multicolumn{5}{|c|}{ PERCENTRAGE ERROR } \\
\hline AOA (deg) & LIFT & DRAG & TANGENTIAL & NORMAL \\
\hline- & $\mathbf{1 . 0 7}$ & $\mathbf{9 . 4 6}$ & $\mathbf{4 . 2 0}$ & $\mathbf{0 . 7 5}$ \\
\hline
\end{tabular}

Table 2: Comparison Analytical and Numerical Values of Aerodynamics Forces.

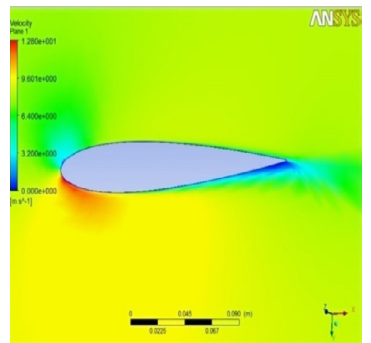

Figure 11: Sectional view of velocity contours on and around blade surfaces.

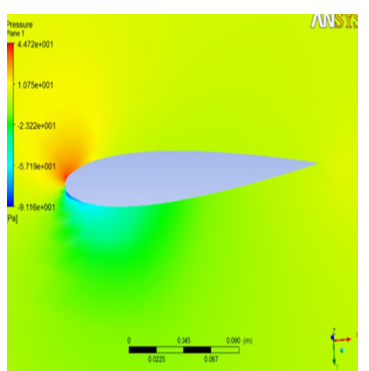

Figure 12: Sectional view of pressure contours on and around blade surfaces.

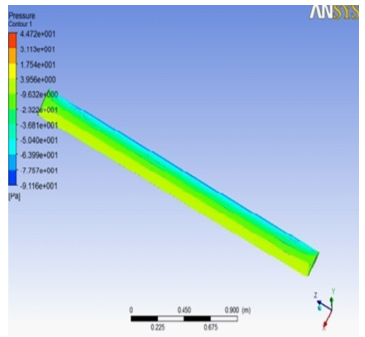

Figure 13: Isometric view of pressure contours on blade surface.

4) The $3 \mathrm{D}$ isometric view of the complete blade after analysis can also be seen in figure 13 .

5) During the analytical analysis of the same blade the values of lift, drag, normal and tangential (axial) forces were calculated [9] at different angle of attacks during the complete rotation of the blade.

6) In numerical analysis, the results are evaluated at a random value of angle of attack and are compared with the analytical results.

7) At $8.36^{\circ}$ angle of attack, the results for both analytical and numerical values are shown in table 2 and a good agreement between the results is found.

8) When CFD results are compared with analytical results, the maximum percentage error is in the case of drag where it is about $9.46 \%$, which is comparable with previous research on the similar blades which shows that this error can rise up to $10 \%$ when compared with the experimental results [3]. As CFD technique is numerical approximation so this error can be further reduced by improving the grid resolution.

\section{Conclusions}

The CFD models can be generated for the evaluation of aerodynamic forces like lift and drag over VAWT blades. These models and numerical 
Citation: Hameed MS, Shahid F (2012) Evaluation of Aerodynamic Forces over a Vertical Axis Wind Turbine Blade through CFD analysis. J Appl Mech Eng 1:116 doi:10.4172/2168-9873.1000116

methods can be used in order to avoid using expensive experimental setups like wind tunnels, for the evaluation of aerodynamic forces over these blades. In the process of analysis, the generation of mesh around the blade is a complex procedure and must be done carefully. If the mesh is not generated properly then there will be a large amount of error and even a small error in the mesh will cause the solution to never converge over the flow region. Solution takes time to converge and results may only be evaluated at a single value of angle of attack during a single run. To get more accurate results increase the discretization of the geometry. While blocking make sure that the required area get blocked otherwise it will affect final results.

\section{References}

1. Cao H (2011) Aerodynamics Analysis of Small Horizontal Axis Wind Turbine Blades by Using 2D and 3D CFD Modelling. MSc thesis, UK.

2. 2D CFD simulation of dynamic stall on a vertical axis wind turbine: verification and validation with PIV Measurements" Carlos Sim̃ao Ferreira Delft University of Technology, Delft, 2629 HS, The Netherlands, American Institute of Aeronautics and Astronautics

3. Sabaeifard P, Razzaghi H, Forouzandeh A (2012) Determination of Vertical Axis
Wind Turbines Optimal Configuration through CFD Simulations. International Conference on Future Environment and Energy, Singapore.

4. Batista NC, Melício R, Matias JCO, Catalão JPS (2012) Vertical Axis Wind Turbine Performance Prediction: An Approach to the Double Multiple Streamtube Model. International Conference on Renewable Energies and Power Quality, Spain.

5. Nobile R, Vahdati M, Barlow J, Dynamic A (2011) Stall for a Vertical Axis Wind Turbine in a two-dimensional study. Mewburn-Crook, University of Reading, Reading, UK, Wind Dam Renewables Ltd.

6. Gupta R, Sharm KK (2012) Flow physics of a combined darrieus-savonius rotor using computational fluid dynamics (CFD)" (INDIA). International Research Journal of Engineering Science, Technology and Innovation 1: 1-13.

7. Chris K, Austin F, Paul Z, Wael M (2012) A CFD Study of Wind Turbine Aerodynamics. Proceedings of the 2012 ASEE North Central Section Conference.

8. Changduk K, Haseung L, Minwoong K Aerodynamic and structural design of a high efficiency small scale composite vertical axis wind turbine blade. Department of Aerospace Engineering, Chosun University, Gwangju, Rep. of Korea, 18th International conference on composite materials.

9. Hameed MS, Afaq SK (2012) Design and analysis of a straight bladed vertical axis wind turbine blade using analytical and numerical techniques. Ocean Eng 57: 248-255. 